\title{
FOTOINTERPRETAÇÃO DA VEGETAÇÃO ATRAVÉS DA DENSITOMETRIA *
}

\author{
Gilberto J. Garcia ** \\ Delmar A. B. Marchetti ***
}

\author{
RESUMO
}

Considerando-se que os critérios fotointerpretativos têm muito de subjetivo, com resultados que variam segundo o fotointérprete, pretendeu-se neste trabalho, ressaltar a utilização da densitometria como auxiliar na fotointerpretação da vegetação.

No estudo foram utilizadas fotografias aéreas coloridas (transparências $23 \times 23 \mathrm{~cm}$ ) na escala 1:6.000. O filme colorido utilizado foi o Kodak Ektachrome MS Aerographic Film 2448.

Desde que as fotografias estavam numa escala grande, foi bastante fácil identificar as culturas existentes na área bem como a vegetação natural. Cada categoria de vegetação foi classificada pela notação de Munsell.

A densidade ótica foi medida por intermédio de um microdensitômetro de transmissão, marca Weston, modelo 877. Para cada item identificado nas fotografias foram feitas lcituras de densidade ótica, para posterior comparação.

Os dados obtidos foram utilizados para avaliar a importância das leituras densitométricas nas transparências coloridas, obtendo-se as seguintes conclusões principais: a) as medidas densitométricas ofereceram resultados mais consistentes que os obtidos por fotointerpretação convencional; b) a utilização do filme infravermelho colorido sugere a possibilidade de ampliar a resposta das leituras densitométricas.

\section{INTRODUÇÃO}

A fotografia aérea apresenta-se como o único instrumento capaz de representar as formas e o arranjo espacial das plantas, individualmente ou em associações. Conforme relata SPURR (1960), a fotointerpretação da vegetação exige basicamente o conhecimento das espécies mais comuns da flora, sua representação em fotografias aéreas e os tipos de plantas que geralmente se associam.

Quanto as características da vegetação, GATES (1970), comenta que a aparência das plantas e das superfícies vegetais depende de sua

* Trabalho apresentado no VII Congresso Brasileiro de Engenharia Agrícola - Pelotas - RS - 1977. Entregue para publicação em 31-10-77.

** Dept. ${ }^{\circ}$ de Engenharia Rural da Faculdade de Ciências Agronômicas de Botucatu - UNESP

*** Dept. ${ }^{\circ}$ de Engenharia Rural da Escola Superior de Agricultura "Luiz de Queiroz" - USP. 
interação com a radiação, sendo influenciada pela geometria das folhas, morfologia, fisiologia, composição quimica, solo e clima.

Conforme assinalam SIMONTACCHI et alii (1955), o importante é a elaboração de chaves de classificaçäo, que podem ser de seleçào ou de eliminação. A seleção seria montada de tal maneira que o fotointérprete seleciona o exemplo correspondente à imagem que estivesse tentando identificar. A de eliminação é montada de tal modo que o fotointérprete acompanha uma sequüência pré-estabelecida, eliminando todos os ítens, com exceção daquele que se deseja identificar. O método de reconhecimento se baseia em parte no estudo da tonalidade, textura, padrão de sombra, forma e dimensão.

Mesmo associado a cor a estes parâmetros, os critérios fotointerpretativos têm muito de subjetivo, variando segundo o fotointérprete. A densidace ótica neste caso, revela-se importante, visto ser um parâmetro de alta repetibilidade.

Os aparelhos que medem a densidade de transmissão é usado para medir a quantidacie de luz que atravessa um filme, enquanto que o densitômetro de reflexão mede a quantidade de luz que reflete da superficie de uma cópia fotográfica (COMPANHIA KODAK, 1972).

A ciensitometria tem sido utilizada com sucesso por vários autores. Assim, MANZER e COCPER (1967) relataram que foi possivel avaliar a severidade da requeima em uma cuitura de batatas, através de medidas densitométricas em transparências infravermelhas coloridas. MURTHA (1969) comenta que foi possível detectar danos fisiológicos em coníferas através de medidas densitométricas de transparências infravermelhas coloridas. JACKSON et alii (1971) obtiveram elevada correlação quando relacionaram medidas densitométricas de uma cultura de batatas com diferentes graus de infestão por requeima, e níveis de infestão obtidos por patologistas, para as mesmas parcelas no campo, evidenciando a utilidade do método.

O trabalho em questão pretende realçar a utilização da densitometria como auxiliar na fotointerpretação da vegetação.

\section{MATERIAL E MÉTODOS}

No estudo foram utilizadas fotografias aéreas coloridas (transparências $23 \times 23 \mathrm{~cm}$ ) na escala 1:6.000. O filme colorido utilizado foi o Kodak Ektachrome MS Aerographic F'ilm 2448. E um filme de granulação fina, velocidade média, reversível, apresentando uma excelente definição e uma boa qualidade de imagem. utilizado para mapeamento e reconhecimento para altitudes baixas a médias. 
Desde que as fotografias estavam numa escala grande, foi bastante fácil identificar as culturas existentes na área, bem como vegetação natural. Cada categoria de vegetação foi classificada pela notação de MUNSEL (1966) .

A densidade ótica foi medida por intermédio de um microdensitômetro marca Weston, modelo 877, de transmissão, com abertura de $0,8 \mathrm{~mm}$. A FIGURA 1, mostra o esquema do aparelho em questão, classificado segundo BLANC et alii (1966) como de resposta calibradu, ou de leitura direta.

Para cada item identificado nas fotografias foram feitas dez leituras de densidade ótica, para posterior comparação.

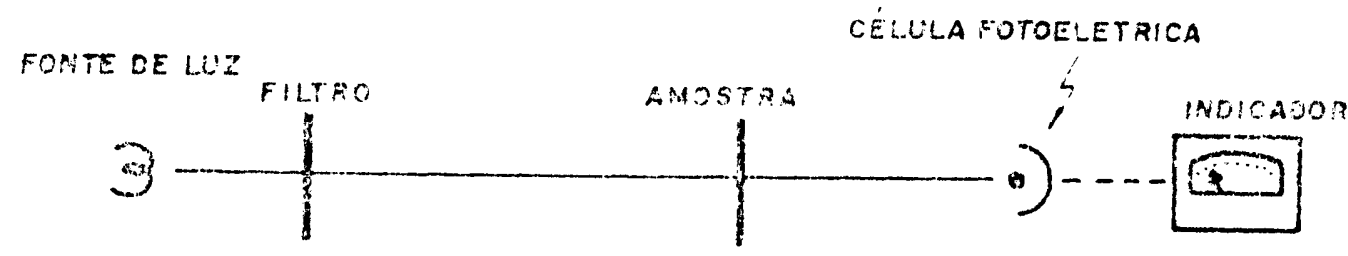

Figura 1 - Esquema de um densitômetro de transmissão.

\section{RESULTADOS E DISCUSSÃO}

O QUADRO 1, mostra os resultados obtidos. Pode-se perceber que tanto a notação de Munsell, como a caracterização da cor, não são tão esciarecedoras como os valores de densidade ótica, a qual possibilitou separar numericamente as diferentes categorias de vegetação. Estas leituras densitométricas, por não se originarem de critério pessoal, podem ser reproduzidas a qualquer momento, desde que se utilizem densitômetros perfeitamente calibrados.

Pode-se perceber ainda pelo QUADRO 1, que existem leituras muito próximas, bem como semelhantes, como é o caso da cana-de-açúcar e eucalipto. Isto decorre do fato de que as plantas na região visível apresentam uma baixa refletividade não diferenciada, crescendo com o aumento do comprimento de onda, apresentando já na faixa pertencente ao infravermelho, uma sensível distinção (GATES, 1970). Utilizando-se, portanto, imagens infravermelhas coloridas, como fizeram MANZER e COOPER (1967), MURTHA (1969), e JACKSON et alii (1971), em associação com imagens coloridas comuns, as possibilidades da fotointerpretação aumentam bastante, principalmente quando se utiliza da densitometria.

E sabido que as dificuldades na fotointerpretação aumentam a medida que diminui a escala fotográáfica. Pode-se dizer que, pela segurança que oferece, a importância da densitometria aumenta a medida que diminui a escala fotográfica. 


\section{CONCLUSŐES}

\subsection{As medidas densitométricas ofereceram resultados mais consistentes que os obtidos por fotointerpretação conven- cional.}

\subsection{A utilização do filme infravermelho colorido sugere a pos- sibilidade de ampliar a resposta das leituras densitométri- cas.}

QUADRO 1 - Cores e densidade ótica para diferentes tipos de vegetação.

\begin{tabular}{llll}
\hline Categorias & MUNSEI.L & Cor & Dens. Ótica \\
\hline Mata alta & 5,7 GY $3,6 / 4,8$ & verde escura & $1,15-1,20$ \\
& 8,0 GY $2,2 / 3,6$ & & 1,10 \\
Cerrado baixo & 5,7 GY $3,6 / 4,8$ & verde escura & 0,88 \\
Campo limpo & 4,8 GY $6,0 / 5,0$ & verde amarelada & 0,90 \\
Campo sujo & 4,8 GY $6,0 / 5,0$ & verde amarelada & 1,08 \\
Café & 5,1 G $3,0 / 8,1$ & verde escura & 1,04 \\
Eucalipto & 5,7 GY $3,6 / 4,8$ & verde cscura & 0,96 \\
Pastagens & 4,8 GY $6,0 / 5,0$ & verde clara & 1,04 \\
Cana-de-açúcar & 5,7 GY 3,6/4,8 & verde cscura & \\
\hline
\end{tabular}

\section{SUMMARY}

FOTOINTERPRETATION OF VEGETATION THROUGH DENSITOMETRY The photointerpretatives paramcters are very subjective, because each photointermeter has his own criterion. The objective of the present work is to evidence the utilization of the densitometry in the interpretation of vegetation.

In the study, were used aerial color photographs (transparences $23 \times 23 \mathrm{~cm}$ ) in the scale 1:6.000. The utilized color film was the Kodak Ektachrome MS Aerographic Film 2448.

Because of the scale sise, was very easy to identify the natural and cultural vegetation. Each type of vegetation was classified by Munsell renotation

The optical density was through a WESTON transmission microdensitometer, model 877. For each type of identified vegetation were made densitometric measurements, for later comparation.

The obtained data were utilized in the evaluation of the importance of densitonteric readings. For the utilized photographs, the main conclusions are: a) the densitometric measurements showed best results comparatively with the convencional photointerpretations; b) the utilization of color infrared film suggest the possibility of a increase in the importance of the densitometric readings. 


\section{LITERATURA CITADA}

BLANC, A.J. et alii. Densitometry. In: Society of Photographic Scientists and Engineers. SPSE Handbook of Photographic Science and Engineering. N. York, 1966 p. 829-877.

COMPANHIA KODAK. Practical densitometry. N. York, 1972. 15 p. (Kodak technical publication E-59).

GATES, D.M. Physical and Physiological Properties of Plants. In: National Academy of Sciences. Remote Sensing. Washington, 1970. p. 224-252.

JACKSON, H.R. et alii. Potato late blight intensity levels as determined by microdensitometer studies of false-color acrial photographs. J. Biol. Phot. Ass. 39: 101-106. 1971 .

MANZER, FE. e COOPER, G.R. Aerial photographic methods of potato disease detection. University of Maine, Bulletin 646. 1967.

MUNSELL COLOLR COMPANY INC. Munsell Book of Color. Baltimore. Mariland, $1966.160 \mathrm{p}$.

MURTHA, P.A. Near infrared detection of simulated animal damage on conifers. Proceedings of Workshop on Aerial Color Photography in the Plant Sciences. Gainesville, Florida, 1969.

SIMONTACCHI, A. et alii. Considerations in the preparation of keys to natural vegetation. Photogram. Eng., 21:582-587. 1955.

SPURR, S.H. Photogrammetry and Photo Interpretation. N. York, Ronald Press. 1960. $472 \mathrm{p}$. 
